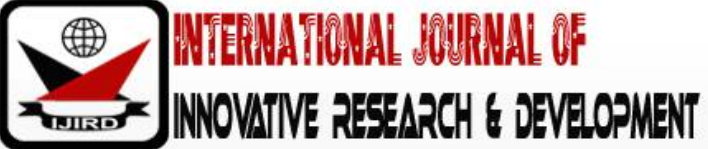

ISSN 2278 - 0211 (Online)

\section{Not-So-Quiet Air Waves; But Is Anyone Listening?}

\begin{tabular}{c} 
Allen Nnanwuba Adum \\
Lecturer, Department of Mass Communication, \\
Nnamdi Azikiwe University, Awka, Anambra State, Nigeria \\
Ogochukwu Ekw enchi \\
Lecturer, Department of Mass Communication, \\
Nnamdi Azikiwe University, Awka, Anambra State, Nigeria \\
Ojinime Ebelechukwu Ojiakor \\
Lecturer, Department of Mass Communication, \\
Nnamdi Azikiwe University, Awka, Anambra State, Nigeria \\
\hline
\end{tabular}

\section{Abstract:}

Broadcasting in this contemporary age has taken a new dimension with the emergence of new communication technologies. This has led to interesting broadcast programmes in the industry. Various radio programmes emerge on the airwaves every day but who listens to these programmes? This study was an assessment of the radio listenership base. It examined the radio programmes students preferred and the impact of these preferred programmes on them. We employed survey method to elicit data from 300 students drawn from Nnamdi Azikiwe University, Awka, Anmabra State; Chukwuemeka Odimegwu Ojukwu University, Igbariam and Madonna University, Okija; all in Anambra State, Nigeria. The findings showed that most students preferred music programme to other radio prorammes. This preference was attributed to the entertainment role musical programmes played in the school life of students. They also claimed such programmes have no negative influence on their studies despite their entertaining nature. We recommended that broadcast stations should make their programmes more entertaining in order to attract and sustain the interest of student listeners who believe in 'less talk; more music', in other programmes that cannot necessarily be in the music format.

Keywords: Radio listenership, radio programmes, music format, air waves, new communication technologies

\section{Introduction}

Radio is a uniquely effective means of disseminating information in terms of overcoming great distances. The original inventors of radio expected it to be used for one-on-one communication tasks where telephones and telegraphs could not be used because of the problems involved in stringing wires from one point to another, such as in ship-to-shore communications. Those inventors had no expectations whatever that radio would become a major mass entertainment and information medium earning many billions of dollars in revenues, annually, through commercial sponsorship (Sungook, 2001). Akpan (1994, p.27) reports that the latter uses of radio were brought about after 1920 by business entrepreneurs such as David Sarnoff, who created the National Broadcasting Company (NBC), and William S. Paley, who built Columbia Broadcasting System (CBS). He notes: These broadcasting (as opposed to narrowcasting) business organizations began to be called networks, because they consisted of loose chains of individual stations located in various cities, all transmitting the standard overall-system supplied fare, often at synchronized agreed-upon times. Some of these stations were owned by the networks, while others were owned by independent businessmen allied with the respective networks. By selling blocks of time to advertisers, the medium was able to quickly become profitable and offer its products to listeners for free, provided they invested in a radio receiver set. The idea of broadcasting, that is, transmitting voices and music at great distances to a large number of people, predated the development of radio. The new medium grew rapidly through the 1920s, vastly increasing both the size of its audience and its profits.

The advent of television changed the relationship between the radio and its audience. There was a time, family gathered around the radio set to listen together, now, we listen to the radio alone. We self-select into pleasing programming formats, and we listen as an adjunct to other personally important activities. We appear to relate personally to radio personalities who we listen to. They play music at our requests, wish us happy birthday and engage in contests with us. Hale (1975, p. ix) described the radio as: The only unstoppable medium of mass communication; it is the only medium which reaches across the entire globe instantaneously and can convey a message from any country to any other. Combined these qualities of radio ensure that it plays an indispensable role in international communications, and keeps its place as the most powerful weapon of intentional propaganda Head, Sterling and Scholfield (1996, p. 47) record that "the status of radio as the most rapid and the most massive of all the media in terms of reach, time spent and popularity has become ever present, seen and felt in almost every home in the Western societies for the reason that it is cheap to own and 
use. Also, that it presents its message with movement and sound." Baran (2004, p. 209) is of the view that mobility of radio accounts in large part for its personal nature. Baran (2004) further holds that "We can listen anywhere [and] at any time. We listen at work; while exercising; while sitting in the sun." The distinctive characteristics of radio serve its listeners, making it a thrilling business. Radio notably refused to die in the face of the rise of television and it has prospered on the basis of several distinctive features. As a medium it has much more channel capacity and therefore greater and more diverse access. It is much cheaper and more flexible in production than television and also cheap and flexible in use for its audience. There are no longer limitations on the place where radio can be listened to or time of reception, since listening can be combined with other routine activities. It has possibilities for interaction with its audience by way of telephone and can accommodate many different genres.

The survival of radio stations is limited in terms of the poor knowledge that radio broadcasters have of their audience's needs and preferences. Bryant and Zillmann (1994, p. 80) are of the view that "majority of current radio stations do not have precise statistics on the nature and composition of their audiences in terms of demographic information, the socio-economic situation of listeners and programme preference." This in turn makes it difficult to develop programming policies geared towards the needs and listening habits of the various audience groups.

The most accessible evidence of how mass communication works is provided by its contents. In a literal sense, we can equate the media with the message, though the distinction between the two is a significant one. The content of mass media has often been regarded as more or less reliable evidence about the society in which it is produced.

The issue of content has become correspondingly more complex and challenging. It may not go too far to say that the most interesting aspect of media content is often not the overt messages, but the many more or less concealed and uncertain messages that are present in media contents.

McQuail (2007, p. 343) reviewed the main motives that have guided the study of media content as follows:

Describing and conquering media output; for more purposes of analysis of mass communication (for instance, assessing change or making comparison), we need to be able to characterize the content of particular media and channels.

Comparing media with 'social reality': A recurrent issue in media research has been the relation between media messages and reality. The most basic question is whether media content does, or should, reflect the social reality and if so, which or whose reality.

Media content: A reflection of social and cultural values and beliefs. Historians, anthropologists and sociologists are interested in media content as evidence of values and beliefs of a particular time and place or social group.

Hypothesizing function and effects of media: we can interpret content in terms of its potential consequences, whether good or bad, intended or unintended.

Evaluating media performance; Krippendorf (2001) used the term performance analysis to refer to research designed to find answers about the quality of the media as judged by certain centers.

The study of media bias: Some media content has a conscious bias, and media production can have systematic but unintended biasing effect on content.

Audience analysis: since audience is always defined at least in part by media content, we cannot study audience without studying content.

Tackling questions of genre, textual and discourse analysis, narrative and other formats. In this context, the text itself is the object of study, with a view to understudying how it works to produce effects desired by authors and readers.

We can approach the question of accounting for media use other than from the side of the audience, asking what influences individual choices and behaviours, or from the side of the media, asking what factors of content presentation and circumstance help to draw and keep audience attention. There is no sharp division between the two, since questions of personal motivation cannot be answered without reference to media products and contents.

Programme preference is largely shaped by certain relative constant elements of social structure and media structure. Social structure refers to social facts such as those of education, income, gender, place of residence, position in the life cycle, and so on, which have a strong determining influence on general outlook and social behaviour.

Weibull (1985, p. 145) opined that "individual with less interest in the media is more influenced by specific contents or by content composition." This helps to explain why evidence about general tastes and preferences does not have a great short-term or individual productive value.

Onah \& Anyanwu (1989, p.59) state that "although, media content is freely chosen by their audiences, actual people in audiences may not have personally chosen the specific content to which they find themselves exposed. This applies where members of the same norm in a hostel are subject to the choices of others about what is available to listen to. That is, a situation where members of the same room (who do not own a radio set) enjoy programme tuned in by their room mate who has a radio. Even where we do choose our own media content, we can easily be dissatisfied with some aspect of media performance and there is much scope for negative responses to the media content."

By its nature, programming is the product of broadcasting and just as a storekeeper sells goods or an accountant sells expertise, broadcasting sells programming. Akpan $(2002$, p.147) saw programming as an "activity that involves the task of designing programmes and scheduling them in meaningful order to ensure success." It is pertinent to note that there is no substitute for good and interesting programmes for the survival of any broadcasting establishment.

With Nigeria taking the dimension of mixed broadcasting, many developments have been attained. Before the inception of privatization of broadcasting in Nigeria as noted by Head $(1974$, p. 339) the country faced the problem of how to reach the whole land area with acceptable contents and how to satisfy the programme needs and desires of a very wide variety of such audiences. Some broadcast stations in Nigeria have built a reputation for themselves, thereby winning the confidence of the population they serve. More preferred station is likely to get more patronage from advertising. Adaba (1995, p.3) has it that "reputation in turn increases the audience." 
Wigwe (1987, p. 23) believes that: The only factor that determines which station people tune to is the quality of the programmes a station renders. It is greatly argued that the practice of private broadcasting if properly managed, will increase chances of attaining survival due to regulatory approach which carefully selects and licenses a qualified broadcaster, even imposing upon the managers the duty of fulfilling the community's tastes and needs. Every day, new programme are introduced, old ones embellished and strengthened to standards with the growing tempo of sophistication. Radio programmes cannot but in the words of Udeajah (2004, p. 2), "blend history and life, time and eternity, reality and legend into a significant mosaic to enhance human aspiration."

Several studies have been conducted addressing numerous questions about media preferences and channel preferences, but Head, Sterling and Scholfield (1996, p. 42) emphasized that "the first priority that stimulates people to buy electronic sets (television and radio), lies only on attractive programmes." It is generally known that audience preference for broadcast stations depends on the content and values of the programmes emanating from such broadcasting stations. More often, the audience choice is a reflection of what these stations are doing especially in satisfying the audience needs. According to Obinyeluaku (1996, p.19), "audience preference for a particular station depends on its programmes." Furthermore, Nwanwanne (1995, p.11) asserted that "programming entails the search for and selection of materials that will satisfy the needs of the target audience."

While it may not be totally out of place for one to ask whether it is important that students listen or do not listen to radio programmes, the relevance of this study becomes clear when one considers that there is tendency to develop some sort of interest in one programme over others. University students rely on radio for information, education, mobilization and entertainment. All of these can be gained through different programmes: news, discussion, music, sports, quiz, drama, talk, interview, documentary, feature and jingles. It is against this background that this work is set.

\section{Purpose}

The major thrust of this study, therefore, was to establish whether university students in Anambra state listen to the radio; examine radio programmes preferences of these students and ascertain the reasons for their preference. The intent was that, identifying these students' listenership and preference for specific programme formats would enable us to determine the listenership base for such programmes among these students. We, accordingly, sought answers to four research questions:

- How many university students in Anambra State, Nigeria, listen to the radio?

- What type of radio programmes do these students prefer?

- How much time do these students spend listening to radio programmes?

- What significant features attract these students to a particular radio station?

\section{Method}

We designed our study as a survey. A 26-item questionnaire was used as the research instrument. A sample of 300 students (based on the statistical suggestion of Comrey [1973]) was drawn from a population of 45,200 students for the three universities that were chosen: Nnamdi Azikiwe University, Awka, Chukwuemeka Odimegwu Ojukwu, University, Igbariam and Madonna University, Okija. Using multistage sampling technique, two faculties were randomly selected from each of the chosen universities. From these faculties five departments, per faculty, were randomly selected. From the selected departments, ten students from each department had the questionnaire administered to them. In all, one hundred students were sampled per university giving a total sample of 300 students for the three universities. We ensured that each respondent owns or has access to a radio set. This enhanced the validity of each respondent's claimed preferred radio programmes.

\section{Results}

The demographic characteristics of our respondents reveal that a majority of the respondents are female (66\%) while $34 \%$ are male. One hundred and eleven of the respondents fall within the age bracket of 18 - 22; 139 were within 23 - 27 years; 47 are within 28 - 32 years; while three of the respondents fell within the age bracket of 33 and above. This shows that those within the age range 23 - 27 years were greater in number (46.3\%) followed by 18 - 22-year olds (37\%) and the least were those within the age bracket of 33and above which represents (1\%). Twenty five percent of the respondents were in first year, $36 \%$ in second year, $23.7 \%$ in third year while $15 \%$ were in fourth year. This picture here is that our respondents were more of the female gender, suggesting somewhat the reality of low male enrolment in schools, in Anambra State, Nigeria; young, and more experienced in the school context.

\subsection{Radio Listenership among University Students in Anambra State, Nigeria}

Our first research question asked to know how many university students in Anambra State, Nigeria, listen to the radio. Questions items $1-5,7,8$, and 9 in the questionnaire were used to answer this research question. All the respondents affirmed that they listen to radio programmes. A greater percentage of the students listen to community radio stations owned by their schools; 31\% listen to Unizik Community Radio 94.1 FM; 33\% of the respondents listen to Madonna community Radio, 93.3 FM; 19\% listen to Coal City FM Radio, 92.9; while 3\% listen to Radio Nigeria, Purity FM, 102.5. Our data show that a greater number of the students listened more to their university's community radio than any other radio station. It could be inferred from this that the participatory nature of community radio generates interest in listening to the radio among these students. 


\subsection{Anambra University Students Preferred Radio Programmes}

Our second research questions sought to determine the radio programmes preferred by the respondents. Questions items 10 -13 were posed for this purpose.

\begin{tabular}{|c|c|c|c|}
\hline S/ N & Programmes & Frequency & Percentage \% \\
\hline 1. & Sports & 62 & 21 \\
\hline 2. & Drama & 0 & 0 \\
\hline 3. & Phone-in programmes & 29 & 10 \\
\hline 4. & Feature & 18 & 6 \\
\hline 5. & Music & 117 & 39 \\
\hline 6. & News & 74 & 24 \\
\hline & Total & 300 & 100 \\
\hline
\end{tabular}

Table 1: Respondents preferred radio programme

The data in Table 1 reveals that a majority of the respondents listen to music on radio (39\%); $24 \%$ listened to news; $21 \%$ went for sports programmes. The respondents who listened mainly to radio phone-in programmes were $10 \%$; Six percent claimed they listened to features while none was interested in radio drama. It could be inferred from these data that a greater number of the respondents listens to music. This might not be unconnected with the relaxation feature of music which most youths, especially, students use to soothe their nerves and escape realities of the school environment.

4.3. The Amount of Time Anambra University Students Spend Listening to Radio Programmes

Items 14 - 19 were posed to elicit answers to research question three. We attempted to determine the amount of time spent by the respondents when they listen to radio programmes.

\begin{tabular}{|c|c|c|c|}
\hline S/ N & Response (hrs Range) & Frequency & Percentage (\%) \\
\hline 1. & $1-3$ & 73 & 24 \\
\hline 2. & $4-6$ & 183 & 61 \\
\hline 3. & 7 and above & 44 & 15 \\
\hline & Total & 300 & 100 \\
\hline
\end{tabular}

Table 2: Quality of Time Spent in Listening to Radio Programmes

Data in Table 2 show that the greater number of the respondents (61\%) listened to radio programmes between 4 - 6 hours daily; $24 \%$ of respondents listened to radio programmes between 1 - 3 hours; while $15 \%$ of the respondents listened to radio programmes for 7 hours or more. We can deduce from our data that the respondents spend quality time listening to radio.

\subsection{The Reasons why Respondents Listen to a Particular Radio Station}

We used items 20 - 26 in the questionnaire to address the research question on the respondents' reasons for listening to a particular radio station.

\begin{tabular}{|c|c|c|c|}
\hline S/N & Response & Frequency & Percentage (\%) \\
\hline & Programmes & 277 & 92 \\
\hline & Proximity & 11 & 4 \\
\hline & Clear Reception & 4 & 1 \\
\hline & Skills of the presenters & 8 & 3 \\
\hline & Total & 300 & 100 \\
\hline
\end{tabular}

Table 3: Reasons for Respondents'Attraction to Particular Radio Stations

Data in Table 3 show that a majority of the respondents (92\%) were attracted to their choice of radio stations because of their programmes. This confirms the findings of other researchers that the audience preference for a station is hinged on certain factors which include programme content of a station. Wigwe $(1981, \mathrm{p} .23)$ believes that the only factor that determines which station people tune to is the quality of the programmes of the station. Also, Head et al (1996, p.42) emphasize that the priority that stimulates people to buy electronic sets lies only on attractive programmes. About four percent were attracted to radio stations of their choice because of the proximity of the radio stations. One percent was attracted to the radio stations due to the clear reception of such radio stations while three percent tune in due to the skills of the presenters of such radio programmes.

\section{Discussion}

The study established that most students listen to radio programmes and most of them listen to those radio stations owned by their schools. The major reason for the choice of a particular radio station was dependent on the programmes emanating from such radio station. This supported the views of earlier researchers and scholars that the audience preference for a station is hinged on certain factors which include programme content of a station. Wiwge (1981, p.23) believed that the only factor that determines which station people tune to is the quality of the programmes of the 
station. Also, Head et al (1996, p.42) emphasized on the priority that stimulates people to buy electronic sets lies only on attractive programmes.

The study revealed that majority of the students preferred music programme, followed by those who preferred news programme. Small percentage preferred sports, quiz and discussion programmes. Students spend little time in listening to radio programmes as can be observed in the study that those who spend more than one quarter of their day in listening to radio programmes were very few.

Significant features that attract students to their preferred programmes include content, nature and presenter of such programmes. Students derive political, social, religious, cultural and global knowledge from their preferred programmes. The study showed that for some students there exist some form of correlation between their preferred programmes and their university career like those studying communication as they look up to those presenters for learning.

Moreover, the knowledge of topical issues goes a long way in broadening their views about life which they gain through discussion and quiz programmes. Surprisingly, those who preferred music progarammes were not left out in this relationship as they claimed that the preferred music programme serves as a companion and an escape from noise during reading. Various suggestions were made by the students on how their preferred programmes could give them optimum satisfaction.

\section{Conclusions}

The students' preference for programmes that are entertaining and informing suggests that the audience select specific type of programme to meet a specific need. This preference was attributed to the roles entertaining programmes play in the school life of students. These include the need for relaxation after tedious exercises in the classroom and field work; the need to curtail distractions during reading; and information roles of such preferred programmes. This supports the idea that entertainment provides reward, relaxation and reduction of tension, which makes it easier for people to cope with real life problems and for society to avoid breakdown.

It is important to note that in programme grouping there must always be overlaps, that is, entertainment programmes should also inform and educate. Students prefer music programmes mostly because they entertain as well as inform them about issues in the society.

\section{Recommendations}

Based on the findings of this study, we recommend thus:

- The broadcast media operators should make better use of entertainment oriented programmes (music, drama, sports) in order to attract and sustain the interest of student listeners who believe in 'less talk' and more entertainment. Since students listen and prefer these programmes, more of them should be introduced in other forms of programmes that are educating and informative so that the interests of students could be arrested and held until the objective of the programme is achieved.

- Also, the broadcast practitioners should make their programmes very entertaining so that students could enjoy them without throwing away the objective of such programmes. News could be diversified; ranging from politics to human angle stories.

\section{References}

i. Adaba, A. T. (1995). The challenges of private broadcasting. A paper presented at the inauguration of the National Society of Broadcasters. National Arts Theatre.

ii. Akpan, C.S. (2002). Sound and sight communication. Enugu: Prize Publishers.

iii. Baran, S. (2004) Introduction to mass communication. Boston: Mufflin Hill.

iv. Bryant, J. and Zillinanm, D. (Eds) (1994). Media effects: Advances in theory and Research. Mahuah, NJ: Lawrence Erlbaum Associates.

v. Hale, J. (1975). Radio Power: Propaganda and International Broadcasting. Philadelphia: Temple University.

vi. Head, S. (1974) Broadcasting in Africa: A continental survey. USA: Voice of America Forum Series.

vii. Head, S. (1996). Broadcasting in America: A survey of electronic media (2 ${ }^{\text {nd }}$ ed) Boston: Houghton Mufflin Company.

viii. Krippendorf (2004) Content analysis 2nd ed. Thousand Oaks: CA Sage

ix. McQuail, D. (2007). McQuail's mass communication theory, London, SAGE Publications.

x. Sungook, H. (2001) Wireless: From Marconi's Black-box to the Audion, MIT Press, page 9 